\title{
Sergio Ramírez, entre dos mundos
}

Luis Alvarenga

para Elena

La vida del escritor nicaragüense Sergio Ramírez ha transcurrido entre los mundos de la ficción literaria y la responsabilidad política. Nacido en la población de Masatepe, en 1942, este autor, el novelista nicaragüense de mayor reconocimiento mundial, y uno de los intelectuales de primera línea de Centroamérica, es también testigo y actor de un período importante de la historia contemporánea de su país. En tanto intelectual, Ramírez es continuador de una tradición muy importante en la cultura latinoamericana. Esa tradición proviene del siglo XIX, cuando las recién emancipadas repúblicas hispanoamericanas intentan fundamentar una identidad política propia. Los intelectuales de esas nacientes repúblicas emprenden una doble tarea: Por un lado, ensayan respuestas sobre las identidades nacionales. Por el otro, buscan fundamentar esas identidades sobre la base de una producción intelectual, cultural y artística, propias. De ahí que esos intelectuales acometan las más variadas tareas: el periodismo, la docencia, la creación literaria, el debate de ideas, la militancia política. Esa urgencia de crear un suelo para arraigar una nueva tradición cultural, los lleva a ser intelectuales polifacéticos, que buscan abarcar el máximo de conocimientos. Tienen, pues, la conciencia de que no hay una tradición: que es preciso crearla. Y en sus hombros asumen esa titánica tarea. Los 
más valiosos intelectuales latinoamericanos de los siglos XIX y XX han aspirado a llenar ese perfil. La generación de escritores a la que Ramírez pertenece no es la excepción.

\section{La vida de Sergio Ramírez}

Sergio Ramírez Mercado proviene, por la rama paterna, de una familia de músicos - los hermanos Ramírez, que protagonizan varios relatos y la novela titulada $U n$ baile de máscaras-. El antepasado más remoto del cual nuestro autor tiene noticia, su bisabuelo, Alejandro Ramírez, tocaba violín desde muy niño, en los años de la guerra contra los filibusteros ${ }^{1}$. Los padres del antepasado del novelista eran músicos errantes, en perpetua gira por los distintos departamentos de Nicaragua. El bisabuelo de Sergio fue entregado por sus padres, "músicos andariegos, pobres de solemnidad" " a un médico que también ejecutaba viola, de nombre Rosalío Cortés, quien se encargó de criarlo. Esto sucedió en Masaya, donde "las orquestas vivían en guerra perpetua. Se disputaban los toques de los oficios religiosos, los bailes de gala y las retretas municipales; enemigos a muerte, los músicos no se dirigían la palabra y más de una vez llegaban a las manos en trifulcas que se escenificaban a media misa, o en las procesiones de los santos ${ }^{3}$ ". Los relatos que los tíos de Ramírez hacían sobre estas "guerras" entre bandas musicales nutren las páginas de su ficción. Uno de los hijos de Ramírez, Lisandro, abuelo de Sergio, echó raíces en Masatepe, se casó a los dieciocho años con Petrona Gutiérrez, con quien tuvo catorce hijos. "Los hijos varones se hacían músicos a medida que crecían. Sólo mi padre, que había sido dedicado a tocar el contrabajo, el instrumento menos divertido y más enojoso de transportar, despreció el oficio. Las mujeres, todas muy bellas como todavía se las ve resplandecer en los retratos de familia, nacieron dotadas de voces melodiosas" ". Entre todos, conformaron la Orquesta Ramírez. Sin embargo, como confiesa Sergio, esta "dinastía de músicos (...) pereció porque ninguno" de los descendientes "aprendimos a tocar un instrumento ${ }^{5}$ ".

No solamente el contacto con una familia de músicos fue decisivo para la formación del futuro escritor. El descubrimiento de los cómics fue crucial: "Mi aventura de escribir empezó en mi infancia, cuando dibujaba historias de secuencias interminables, cuyos trazos me llevaban, tiza en mano, la cara contra los ladrillos, por todo el piso de la

\section{0}


tienda de abarrotes de mi padre, en mi casa de Masatepe. Así entré en el rapto de la ficción, describiendo más que escribiendo, retratando personajes y escenarios, transformando la imaginación en líneas más que en palabras. Sería porque mi infancia estuvo marcada, no por las consabidas lecturas de Emilio Salgari y Julio Verne, que todo escritor anota entre sus primeras experiencias, sino por mi pasión desmedida por las historietas cómicas, Spirit, El Capitán Marvel, El Fantasma, pasión que me consumía hasta pasada la medianoche, alumbrando sus páginas coloridas con un foco de mano escondida entre las sábanas para no provocar en mi madre recriminaciones por mi desvelo". Las radionovelas, esos trasuntos de las novelas de folletín decimonónicas, pero, sobre todo, el cine, le dieron a Sergio la clave para construir sus recursos narrativos. A los doce años ya mostraba una vocación literaria en proceso: había enviado a una radio local unos guiones cómicos que fueron pasados al aire, ganando así un concurso cuyo premio eran "dos botellas del ron que patrocinaba el programa. Este sería el primero, y uno de los pocos, de los premios literarios que he recibido en mi vida $^{7}$ ". A esa misma edad, entró a trabajar como proyeccionista del único cine que existía en Masatepe, propiedad de su tío Ángel Mercado. "Así me aprendí, de memoria, La llamada fatal, de Alfred Hitchcock, El séptimo sello, de Ingmar Bergman, Rashomon, de Akira Kurosawa, Arroz amargo, de Giussepe De Santi, raras selecciones que mi tío hacía en los catálogos de las casas distribuidoras en Managua, como buen amante del cine que fue, sumadas a innumerables películas mexicanas que hoy alimentan mi nostalgia, enamorado hasta hoy de los rostros de Meche Barba, Dolores del Río, Gloria Marín, Elvira Quintana ${ }^{8}$, recuerda.

Su primera publicación fue hecha a los catorce años. Se trata de un cuento basado en una leyenda, La carreta nagua - probablemente, la leyenda que conocemos en El Salvador como La carreta chillona, que salió en las páginas del suplemento cultural de mayor tradición en Nicaragua, La Prensa Literaria, en el año de 1956. La Prensa Literaria fue dirigida durante mucho tiempo por el fallecido poeta Pablo Antonio Cuadra, uno de los grandes de la poesía nicaragüense del siglo XX. En la actualidad, el suplemento es dirigido por la poeta Marta Leonor González. Publicar en La Prensa Literaria ha sido, y es, una prueba de calidad que los escritores de Nicaragua han tenido - y tienen- que pasar. Eso dice mucho de la vocación literaria de Sergio a 
los catorce años de edad. Su caso es particular: desde siempre escribió narrativa, cuando la regla común es comenzar escribiendo poesía e incursionar en el relato más adelante.

En 1959, se traslada a la ciudad de León para cursar estudios universitarios en Derecho. Junto a Fernando Gordillo funda la revista Ventana e incursiona en las organizaciones estudiantiles que luchan por el respeto a la autonomía universitaria. Por ello, a los intelectuales de su edad se les agrupa bajo el marbete de "Generación de la autonomía".

Publica, en 1963, su primer libro, Cuentos, en una tirada artesanal, lo cual reafirmó la temprana vocación de escritor de Sergio. "Mi padre recibió aquel libro con orgullo, ya resignado al hecho ineluctable de que nunca abriría mi bufete de abogado en mi casa de Masatepe", recuerda. "-Ahora -me dijo- tenés que escribir una novela. Y empecé a escribir mi primera novela, Tiempo de fulgor, que se publicó en Guatemala en 1967, en la que de alguna manera contaba mi tránsito de Masatepe a León, del poblado de indígenas y ladinos a la ciudad colonial que aún vivía, igual que hoy, bajo la sombra tutelar de Rubén Darío" ". Se exilia con su esposa Tula y sus hijos María, Dorel y Sergio, en San José de Costa Rica, donde ejerció la dirección de la Editorial Universitaria Centroamericana, EDUCA, proyecto editorial de la entidad que agrupaba a las universidades públicas de Centroamérica, el Consejo Superior Universitario Centroamericano, CSUCA. Le sustituyó en el cargo el poeta salvadoreño Ítalo López Vallecillos. Durante el tiempo en que ambos escritores la encabezaron, EDUCA fue una de las editoriales más influyentes de la región. Años después, en 1973, se traslada con su familia a Berlín, gracias a que obtuvo una beca para escribir su novela ¿Te dio miedo la sangre?. En la metrópoli alemana trabaja la primera versión de El pensamiento vivo de Sandino, libro que completaría después del triunfo sandinista, cuando tiene acceso a los archivos de la Marina estadounidense.

Durante todo ese tiempo, el dictador Anastasio Somoza Debayle gobernaba el país con mano férrea después de la muerte de su padre, el iniciador de la dinastía Somoza, quien se había hecho con el poder décadas atrás. Es decir, la infancia y la juventud de Ramírez están marcadas por el somocismo, que controla todos los aspectos de la vida nacional. El somocismo se caracterizó por una fuerte represión a cargo de la Guardia Nacional, creada expresamente para relevar a los 
marines estadounidenses que habían ocupado el país; por la concentración de poder económico en manos de la familia Somoza o por sus allegados $y$, además, por la veneración incondicional del caudillo, Anastasio Somoza, expresada en la proliferación de monumentos, estatuas ecuestres y edificios o estadios con el nombre del dictador.

Como hemos dicho, Ramírez está vinculado desde joven al movimiento universitario autonomista. En 1975, vuelve a Centroamérica para unirse a la lucha antidictatorial. Ingresa al Frente Sandinista de Liberación Nacional (FSLN). "La decisión de dejar Alemania quedó sellada para mí la noche de invierno de finales de 1974, en que el Tagesschau, el noticiero de televisión que veíamos antes de la cena, se abrió con una información sorprendente. Un comando sandinista había tomado por asalto en Managua la residencia de un barrio elegante, donde se celebraba una fiesta, y mantenía como rehenes a familiares y ministros de Somoza ${ }^{10}$, escribe. El hecho tuvo lugar en la mansión de un allegado del dictador, José María Castillo, durante una recepción en honor al embajador de Estados Unidos en Managua. Integra el Grupo de los Doce, conformado por figuras de la oposición antisomocista. Cuando decide ingresar nuevamente a Nicaragua, en 1978, el tirano ha dispuesto una orden de presión en contra suya.

La insurrección desatada por las fuerzas sandinistas ese año, trae consigo la derrota del Estado Mayor somocista y la huida del dictador y su familia a Miami, en julio de 1979. Asume el poder una Junta de Reconstrucción Nacional, integrada por representantes de la oposición a Somoza, desde empresarios conservadores hasta comandantes sandinistas. Sergio es designado Vicepresidente de la Junta. Al deshacerse esta y convocarse a elecciones, el escritor asume la Vicepresidencia de la República, con el comandante sandinista Daniel Ortega Saavedra en la primera magistratura del país. Forma una parte de la Dirección Nacional del FSLN.

Ramírez asume sus tareas políticas, no sin descuidar su responsabilidad como escritor. Incluso, bajo el asedio de la llamada contra -antiguos guardias somocistas entrenados y armados por Washington-, Ramírez escribe una de sus más famosas novelas, Castigo divino, que sería adaptada a la televisión en Colombia.

Una prueba dura que Sergio tuvo que afrontar - así como toda la militancia sandinista - fue la derrota electoral del FSLN en 1990. La 
fórmula electoral del sandinismo, con Ortega y Ramírez a la cabeza, es vencida por Violeta Barrios de Chamorro, directora del diario La Prensa y viuda de un carismático periodista, asesinado por Somoza. En un gesto valiente, Daniel Ortega reconoce el triunfo de Violeta Chamorro y afirma que el FSLN respetará la decisión popular.

La época posterior a la derrota electoral es la culminación de un proceso de deterioro del sandinismo, causado por el desgaste político, la corrupción de algunos dirigentes y el cansancio popular ante la situación de guerra provocada por los Estados Unidos. Las discrepancias en el FSLN afloran. Se escinde del Frente un grupo denominado Movimiento de Renovación Sandinista (MRS), en el cual Ramírez forma parte. Más tarde, Sergio se aleja de toda actividad partidaria y se dedica a la literatura. En 1998, obtiene el Premio Internacional Alfaguara de Novela, con Margarita, está linda la mar, compartido con el libro Caracol Beach, del cubano Eliseo Alberto - hijo del poeta Eliseo Diego-. El jurado del certamen estuvo compuesto por figuras de primera línea, como Carlos Fuentes, Tomás Eloy Martínez, Sealtiel Alatriste, Rosa Regàs y Marcela Serrano. El acta del jurado afirma: "Con esta historia, y con un lenguaje de constante belleza, Sergio Ramírez construye una novela en la que caben la poesía, la ciencia, las crueldades y los delirios de América en este siglo. Es una obra total, rebosante de pasión y de nobleza literaria ${ }^{11 "}$.

En la actualidad, Ramírez divide su tiempo entre el periodismo dentro y fuera de su país - publica una columna semanal en un matutino salvadoreño-, la enseñanza de la literatura y la creación. Sus publicaciones más recientes son Mentiras verdaderas, donde expone sus ideas sobre la ficción narrativa y el tomo de relatos Catalina $y$ Catalina. Acaba de publicar una novela en México y España, Sombras nada más, la cual comentaremos detenidamente.

\section{El universo ficcional}

La literatura se nutre de las obsesiones del autor, lo que Sabato llama "los fantasmas" y Vargas Llosa alude como "los demonios" del escritor, los íntimos tormentos y placeres que alimentan la creación de mundos poéticos, narrativos o ensayísticos. El conjunto de la narrativa de Sergio — que está lejos de considerarse clausurado- tiene lo que yo llamaría ciclos, término que tomo prestado de las obras de 
caballería, y que ocupo para señalar esas obsesiones - llamadas también, de un modo más elegante, "temas"-, a las cuales el autor vuelve cíclicamente.

El ciclo que mayormente destaca en la obra de Ramírez es "El ciclo de S.E.", y está vinculado al personaje del Dictador. Ese Dictador - conocido en De tropeles y tropelias bajo el tratamiento de Su Excelencia (S.E.) - y que, siendo fiel a su identidad, dicta leyes que regulan a los individuos, a las bestias, las fiestas y espacios públicos, etc. S.E. raras veces aparece directamente enfocado en la obra de Ramírez. En De tropeles y tropelias lo que aparece no es él: es su poder, expresado en la palabra - la palabra de decretos esperpénticos y totalizantes-. El narrador, sin quererlo, es un doble benigno de S.E.: legisla con la palabra sobre el mundo de la ficción.

Luego, y por un período muy significativo, S.E. no vuelve a ser aludido directamente en la obra de Ramírez: lo que aparece es su sombra, que se alarga sobre los destinos humanos, como en el caso del beisbolista acusado de sedición y asesinado bajo la costumbre de la "ley fuga", en el cuento El Centerfielder. Exagerando quizás las cosas, podemos decir que la aparición de S.E. en planos que lo enfocan directamente - al punto que deja de ser S.E. y se le nombra totalmente- es en la novela Margarita, está linda la mar. Esta operación de nombrarlo y de verlo a la cara servirá para que se vaya configurando una identidad paralela: la del poeta que lo asesinará a tiros durante una fiesta ofrecida en su honor.

\subsection{Sombras nada más, lo humano, demasiado humano}

La trama de esta novela transcurre en unas pocas horas: las que le quedan de vida a un colaborador de Somoza mientras espera el juicio popular que lo llevará al paredón. Son las postrimerías de la guerra revolucionaria que llevó al triunfo sandinista de 1979. El protagonista, Alirio Martinica, se ve forzado a "revisitar" uno a uno los hilos que tejieron la trama de su vida.

La ejecución de Martinica es real. Fue uno de los tantos ajusticiamientos decididos en los Tribunales Populares instituidos para "limpiar" los territorios ganados por los sandinistas de miembros de la tenebrosa Guardia Nacional y colaboradores del antiguo régimen. Uno de los méritos de Ramírez es colocar un hecho -que normalmente suscita 
condenas o aplausos - en sus más variados ángulos, de tal manera que no hay lugar para los juicios simples.

Ramírez no es de los escritores que, como suele decirse, "se duermen en sus laureles". Todavía se encontraba en la gira promocional de una novela anterior, Margarita, está linda la mar —con la que ganó el Premio Alfaguara, junto a Lichi Diego-, cuando la historia de Martinica comenzaba a obsesionarle. La suerte loca que acompaña a los escritores hizo que, estando en Miami, pudiera conocer a la viuda de Martinica -cuyo padre, según escribe Sergio, aparece en ¿̇e dio miedo la sangre?-. De esta manera, la novela fue tomando cuerpo.

No es raro que para un creador que ha hecho de la historia de su país su campo narrativo este personaje se haya trocado en obsesión: Alirio Martinica llevó una vida azarosa: fue dirigente del Frente Estudiantil Revolucionario (FER), afín al sandinismo; luego, como tantos otros que "maduran", abandonó los "ideales locos de juventud" e hizo algo práctico: se casó con una mujer de familia adinerada y llegó a ser secretario de Somoza, antes de caer en desgracia por aquello que un cronista decimonónico podría llamar "una intriga palaciega" que lo hundió en el lodo. Cuando gozó de los privilegios del poder, Martinica fue testigo de las disputas entre la esposa del dictador, Hope Portocarrero, y la amante de éste, a quien se llama en el libro La Pérfida Mesalina, pero cuyo nombre real fue Dinorah Sampson. Hay alguna fotografía de ella en traje de baño: se ve por qué su belleza volvió loco al dictador. La Pérfida Mesalina logró que Somoza se separara de Portocarrero, con quien únicamente aparecía en actos públicos, por obvias razones de imagen. Sobre la relación del dictador con Sampson, el comandante sandinista Tomás Borge escribió: “A mi juicio, Somoza, siendo un monstruo moral, el amor por esa mujer lo convirtió en un ser humano".

Humano, demasiado humano, como todos los personajes de Sombras nada más. Porque es muy fácil juzgarlos según las elecciones que uno ha hecho en su vida. Es fácil escamotear cosas desagradables y justificar o condenar los hechos sin matices. Así que esta novela de Sergio implica también un desafío para quien la lee. Su mirada se vuelve implacable, y no cede ante los antifaces que pone la ideología y la piedad mal entendida. 
Uno de los personajes, el comandante guerrillero Nicodemo, quien había sido amigo de juventud de Martinica, y conduce los interrogatorios de éste, afirma: "Las minucias, errores, abusos, injusticias, se entierran en el olvido cuando hay acontecimientos tan variados y vertiginosos como los que ocurren en una revolución, y muchos actos heroicos corren la misma suerte, aunque hayan servido de palanca al salto de la historia". Los grandes discursos sobre la Historia se tragan las pequeñas historias, las insignificantes historias donde se juega la vida y la muerte de hombres y mujeres concretos.

Pero tras los grandes discursos, avanzan reptando, las pasiones humanas. En la ejecución del protagonista convergen varios personajes: el ya mencionado Nicodemo - ex jesuita incorporado a la guerrilla-, cuyo discurso revive esa aura de austeridad y moralidad cuasi religiosa propia de los "primeros cristianos" que, según el propio Ramírez, tuvo el sandinismo en su etapa clandestina; el comandante guerrillero MancoCápac - que, en un gesto humorístico muy centroamericano, escogió ese seudónimo tras haber perdido una mano-, la guerrillera Judith -que participó en el asalto a la casa de un funcionario somocista y que sirvió de carnada para la ejecución de un torturador del antiguo régimen - y una multitud que aguarda con excitación el momento en que Martinica salga para condenarlo a muerte.

La trampa fácil es hacer que los guerrilleros aparezcan como sedientos de sangre, y que Martinica se vea como una inocente víctima. Ramírez es demasiado buen novelista como para caer en la celada. Ni santos ni demonios: en las motivaciones de los personajes se mezclan los más altos ideales con la carroña; los pecados capitales con la generosidad; la lujuria, la sed de venganza y la codicia con el desprendimiento y la generosidad. El novelista nicaragüense trata de decirnos que el período del sandinismo no puede verse como "los ríos de leche y miel" que prometía el himno revolucionario, pero tampoco como el último gulag latinoamericano. En un proceso histórico que liberó a Nicaragua de una dictadura ominosa y rescató un sentimiento de dignidad y humanismo, también se cometieron muchas cosas éticamente condenables. Tan inadmisible como condenar el proceso revolucionario en bloque, es el decir que todos sus autores fueron ángeles. Pero volviendo a los personajes de Sombras nada más —un título por lo demás acertado, no sólo porque Martinica trata de moverse a la sombra del poder, sino porque el libro es un "viaje al corazón de la oscuri-

\section{7}


dad"- éstos guardan tanto del alma humana que un lector mínimamente cómplice puede sentir por ellos las emociones más contradictorias.

Hay otro personaje que aparece en el libro, pero que no tiene un nombre concreto: es esa muchedumbre cuyos miles de ojos - como el mítico Argos- sólo pueden ver la puerta cerrada del recinto donde se interroga a Martinica, y cuyas gargantas son tan temidas como el pulgar de los emperadores romanos en el Circo. La escena del Tribunal Popular me recuerda aquellos pasajes de la Pasión: la multitud quiere jugar a condenar y absolver. Absuelve, no al que tiene un destino trágico - del cual, por lo demás, no puede librarse-, sino al que gana su complacencia, como lo logra el personaje conocido como Niño Lobo, quien hace gala de una locuacidad impresionante, capaz de transformar su inminente condena en absolución $-\mathrm{y}$ encima, valerse de esto para integrarse a la vida normal durante el sandinismo-. Es decir: no se puede esperar justicia de un tribunal amorfo como es la masa. La masa es toda emociones y es susceptible de ser conducida: por eso es masa. Al constituirse en masa, los individuos abdican de su facultad de elegir —esto es, de aquello que les confiere humanidady pasan a indiferenciarse. No puede haber individuos en una masa: quien se diferencia, automáticamente se excluye de aquélla. Esto es lo que ocurre con la multitud de la novela -aunque Sergio se encarga hábilmente de introducir matices: consigna los momentos de discrepancia, pero aquí lo que ha ocurrido es que la masa simplemente se ha dividido en bloques, no se ha disuelto en la elección individual, aunque ésta, paradójicamente, es lo que mantiene la cohesión de esa "masidad"-. El problema de la masa - la "cuestión de las masas", que decía Ignacio Ellacuría- es esa abdicación de la capacidad electiva y crítica. Un proceso liberador no puede apoyarse en la "masidad", pues no hay tal liberación del ser humano.

En suma, esta novela tiene mucha tela que cortar. No dudo que vaya a suscitar polémica en Nicaragua, como ya lo hizo Castigo divino, sobre todo porque el autor fue lo suficientemente audaz para abordar el período revolucionario desde un punto de vista que no admite posiciones cómodas. Sabe que las novelas y la literatura en general, no son para entretener, sino para provocar, suscitar ideas y emociones. Quien lee un libro como éste y sigue tranquilo, necesita aprender a leer de nuevo. 